\title{
TENSIONES EN EL POBLAMIENTO ANDALUZ Y PROBLEMAS DE ADMINISTRACION TERRITORIAL: EL CASO DE ISLA MAYOR *
}

Jesús VENTURA FERNANDEZ**

\section{PRESENTACION}

Se trata de realizar una valoración general de Ios conflictos que sobre el solar andaluz se desarrollan en función de la problemática de su administración territorial. Para ello haremos una presentación de la tipología del complejo poblamiento regional, así como de sus orígenes y condicionantes actuales -lo que supone la destilación de un estudio analítico anterior (VENTURA y AYALA, 1987)-, para avanzar posteriormente sobre las tensiones que se manifiestan a escala tanto local como comarcal. En este sentido abundaremos en el caso segregacionista de Isla Mayor-Villafranco del Guadalquivir, como ejemplo que nos sirva para profundizar en el tema y extraer algunas conclusiones extensibles a un conjunto de procesos similares, tan convulsivos en los últimos años.

\section{TIPOS DE POBLAMIENTO Y CONDICIONANTES}

\subsection{Reconocimiento del territorio}

El poblamiento de Andalucía se ha venido identificando con una imagen de grandes pueblos (las ciudades-aldeas de Manuel de Terán) a la que se superponía una fina malla de pequeñas unidades de explotación agraria (los cortijos andaluces). Sin embargo, hoy por hoy, esa simplificación resulta inaceptable para la generalidad de la Comunidad Andaluza.

* Este artículo deriva fundamentalmente de los estudios realizados por el autor para el trabajo de investigación correspondiente al Programa de Doctorado "Política Regional y transformaciones territoriales”, impartido por el área de Análisis Geográfico Regional de la Universidad de Sevilla.

** Profesor Asociado de Análisis Geográfico Regional de la Universidad de Sevilla. 
En efecto, si tenemos en cuenta tanto el concepto de poblamiento entendido como la distribución de asentamientos sobre el territorio, como la noción complementaria de población -de carácter más o menos denso-, nos resulta una interesante tipología de espacios andaluces. Estos comprenderíän una franja septentrional con poblamiento concentrado y población escasa o dispersa; el Bajo Guadalquivir con población y poblamiento concentrado; la zona oriental de la región con población y poblamiento disperso; y el litoral mediterráneo con poblamiento disperso y población concentrada (MARCHENA GOMEZ, 1984). Sólo en una poco definida, pero extensa área central encontramos el típico poblamiento concentrado con hábitat intercalar antes referido, muy condicionado en estos momentos por una población en franca decadencia.

Además habría que tener en cuenta que esta esquematización se encuentra matizada por las tendencias actuales de la demografía y el poblamiento regional. Así, dentro de una tónica general de reducción de la población rural -determinada por la crisis de las estructuras agrarias tradicionales que incide especialmente sobre los asentamientos menores y deseminados-, encontramos como en Sierra Morena el proceso de despoblación es evidente; en el litoral la multiplicación de nuevos asentamientos relacionados con una dinámica económica propia también es notable; el sector oriental se encuentra en recesión, tanto demográfica como de establecimientos humanos (sobre todo los de carácter aislado que tradicionalmente se han aglutinado en esta zona); y sólo el triángulo Huelva-Sevilla-Cádiz (más estable en los últimos años) parece mantener sus características en cuanto a población y poblamiento.

Por su parte la heterogénea área central se ha visto sumamente impactada por la mencionada crisis agraria, y en general ha perdido tanto población como entidades de asentamiento. Son en este sentido los cortijos, haciendas, caseríos y otras viviendas de tipología diseminada las primeras que han sufrido la menor demanda de mano de obra para las tareas agrarias y la superación de la necesidad de residir en las proximidades del terrazgo a raíz del desarrollo de los medios de transporte (VENTURA y AYALA, 1987).

En cualquier caso todos estos cambios están relacionados con el creciente proceso de concentración económica (JORDA BORRELL, 1987) que afecta a nuestra Comunidad, y que determina la polarización humana (MARCHENA GOMEZ, 1987) en enclaves urbanos significativos: capitales de provincia, litoral, algunos municipios sobre la N-IV. De forma paralela el medio rural sufre en general un desenganche de los modos de desarrollo y un evidente retroceso demográfico que se traduce en la desaparición de los pequeños asentamientos y sobre todo del hábitat diseminado, más sensible a los factores antes apuntados.

Todo este análisis nos permite situar en su justa medida el fenómeno del 
poblamiento andaluz y sus tendencias actuales como paso previo antes de ahon dar en la cuestión principal que aquí nos ocupa: las relaciones entre la trama dt asentamientos y los problemas de la administración territorial en Andalucía. Er este punto la situación es, como veremos, compleja, pues junto al llamado "sa. rampión segregacionista" (núcleos que pretenden separarse de su ayuntamiento) la Administración Pública intenta fomentar las asociaciones municipales de di. verso tipo (mancomunidades, consorcios, áreas metropolitanas).

\subsection{Influencia de distintos factores}

La estructura del poblamiento andaluz obedece a la conjunción de factores d distinta índole: histórico-administrativos, físico-naturales y socio-económicos Son quizás los primeros los que determinan de manera más evidente la actua trama de asentamientos andaluces, muy marcada por el dilatado devenir de hombre sobre nuestra región (poblada desde los albores del Paleolítico) y sus antiguas formas de ocupación estable (iniciadas en el Neolítico con la cultura de El Argar). Este hecho, generalizado para el conjunto del mundo mediteráneo está también muy relacionado con un elemento básico del medio natural como es la red hidrográfica y las consiguientes posibilidades de captación de agua, que han favorecido, desde siempre, en un ámbito de precipitaciones escasas e irregulares, la localización de los asentamientos humanos.

Otros aspectos históricos a tener en cuenta son las intervenciones públicas sobre el entramado de núcleos, que podemos sintetizar en dos momentos principales. Por un lado las llamadas "Nuevas Poblaciones de Sierra Morena y Andalucía", levantadas por el gobierno ilustrado de Carlos III para repoblar el Caminc Real (ruta Cádiz-Madrid) y rescatarlo así del poder del bandolerismo; que ș concentraron en torno a La Carolina en la Sierra Morena jiennense (TYRA. KOWSKI, 1988) y a La Carlota en Ia Campiña sevillano-cordobesa. Y por otrc parte la denominada colonización agraria de Andalucía, con antecedentes en e S. XIX y primeras décadas de nuestro siglo, pero que se desarrolló con fuerza er la posguerra civil a través de la labor del INC/IRYDA; organismos que ejecutaron alrededor de un centenar de asentamientos de diverso tipo (poblados $d \epsilon$ colonización, barriadas, ampliaciones de núcleos) sobre las nuevas zonas regables (en la vega del Guadalquivir mayoritariamente) (ORTEGA, 1979). La iniciativa privada también ha jugado un papel destacado, aunque de incidencia más puntual, en la creación de entidades en espacios en su momento de nueva explo. tación económica, como la campiña jerezana o las "islas" del Guadalquivir en li zona marismeña. 
Sin caer en un falso determinismo debemos ponderar igualmente la influencia del medio físico en la trama de asentamientos, de modo que la morfología montañosa de la zona oriental de Andalucía ha favorecido la dispersión de los establecimientos humanos, mientras que la Baja Andalucía permite la concentración en un menos número de núcleos. No obstante, en todo este proceso ha tenido mayor peso la tradicional organización colectiva del trabajo agrario en la Andalucía del Valle ("villae" romanos, "maysar" islámicos, cortijos de campiña,...), reforzada por la repoblación rural de carácter extensivo que tuvo lugar desde el S. XIII y que motivó incluso la desáparición de algunas entidades (fenómeno de los “despoblados") (GONZALEZ JIMENEZ, 1980). Por el contrario en el antiguo Reino de Granada el peso de las grandes explotaciones (de más de 200 has.) no ha sido tan importante, y apenas sobrepasan en la actualidad el $50 \%$ de la superficie agraria total (OCAÑA OCAÑA y GARCIA MANRIQUE, 1990). Este hecho se vio remarcado por la densificación demográfica de los siglos XIV y XV, cuyos efectos perduraron hasta la centuria pasada cuando se inició la particular sangría emigratoria de la zona oriental de Andalucía.

El dinamismo o retroceso económico de las distintas zonas de nuestra región incide también de manera notable en la creación o supresión de entidades de población en Andalucía. Así la multiplicación de asentamientos costeros está esencialmente relacionada con el turismo litoral; y la aparición de residencias periurbanas con la expansión de las ciudades andaluzas. Por su parte en espacios regresivos como los serranos o de campiña ya hemos apuntado la tendencia al despoblamiento de sus entidades menores.

Con todo esto sólo pretendemos situarnos sobre la amplia gama de condicionantes del poblamiento regional, que van a determinar en gran medida-creemos que en ocasiones fundamentalmente-, algunos de los principales problemas de la administración del territorio en Andalucía, entendida ésta como la organización y gestión de un espacio más o menos diverso.

\section{LA ADMINISTRACION TERRITORIAL DE LOS MUNICIPIOS ANDALUCES}

\subsection{Planteamiento de situación}

La región andaluza no escapa, como es lógico, a la internacionalización económica y en menor medida política que afecta al conjunto de la comunidad mundial. En este sentido la integración de España, y con ella de sus Comunidades Autónomas, en organismos supraestatales de diverso tipo refuerza esta ten- 
dencia hacia la pretendida "aldea global". Sin embargo estos procesos no debel hacernos olvidar que, aunque las grandes directrices se tomen cada vez más lejo de nuestras fronteras, parece evidente que la gestión concreta del territorio e más efectiva cuanto más se acerque al ciudadano. Es por ello que, en un marc de alteración de las escalas administrativas (procesos generalizados de descen tralización), se plantea con fuerza la transformación también de los niveles loca les.

En España sabemos que por mandato constitucional la Administración Loca está compuesta por provincias y municipios. Las primeras obedecen a una men talidad centralizadora cuya antigüedad se remonta a poco más de 150 años, । incluso han "sufrido" algunos intentos de supresión en comunidades de mayo conciencia regional. En Andalucía el proceso de comarcalización (JUNTA DF ANDALUCIA, 1983), coherente con la descentralización actualmente vigente, : que ni siquiera pretendía la eliminación provincial, ha quedado como tal en agui de borrajas y sólo perdura como teórica jerarquización de centros y como marcc territorial para la aplicación de algunas políticas sectoriales (JUNTA DE ANDA LUCIA, 1986).

Por su parte los municipios tienen en general un origen mucho más antiguo medieval en la mayoría de ocasiones (M. O. P. U., 1980), y suelen corresponder se con un espacio organizado por un asentamiento principal con un territoric periférico sobre el que aparecen con frecuencia algunas entidades menores. Nc obstante esta simplificación es susceptible de diversas matizaciones. Todos co nocemos casos de micromunicipios (abundantes en la Sierra de Aracena eI Huelva, Aljarafe sevillano o Vega de Granada) y también términos muy extenso: de escala casi comarcal (Córdoba o Jerez de la Frontera por ejemplo). Igualmen te en ocasiones encontramos municipios sin una cabecera clara o con vario: núcleos que se disputan la hegemonía.

Son todos estos problemas, su origen y las consecuencias que tienen para li administración territorial, los que trataremos de presentar a continuación desdt una doble vertiente: por un lado su incidencia en la problemática intramunicipa y por otra en la intermunicipal.

\subsection{Enclaves y segregaciones}

A nivel inframunicipal cabe hablar a su vez de dos tipos básicos de proble mas territoriales derivados de la estructura de poblamiento: los municipios dis continuos, esto es, aquéllos cuyo término está fragmentado; y los movimiento: segregacionistas que afectan a una serie importante de ayuntamientos. 
MAPA I

PRINCIPALES MUNICIPIOS DISCONTINUOS DE ANDALUCIA CON INDICACION DEL TERMINO SEPARADO DEL NUCLEO CAPITAL

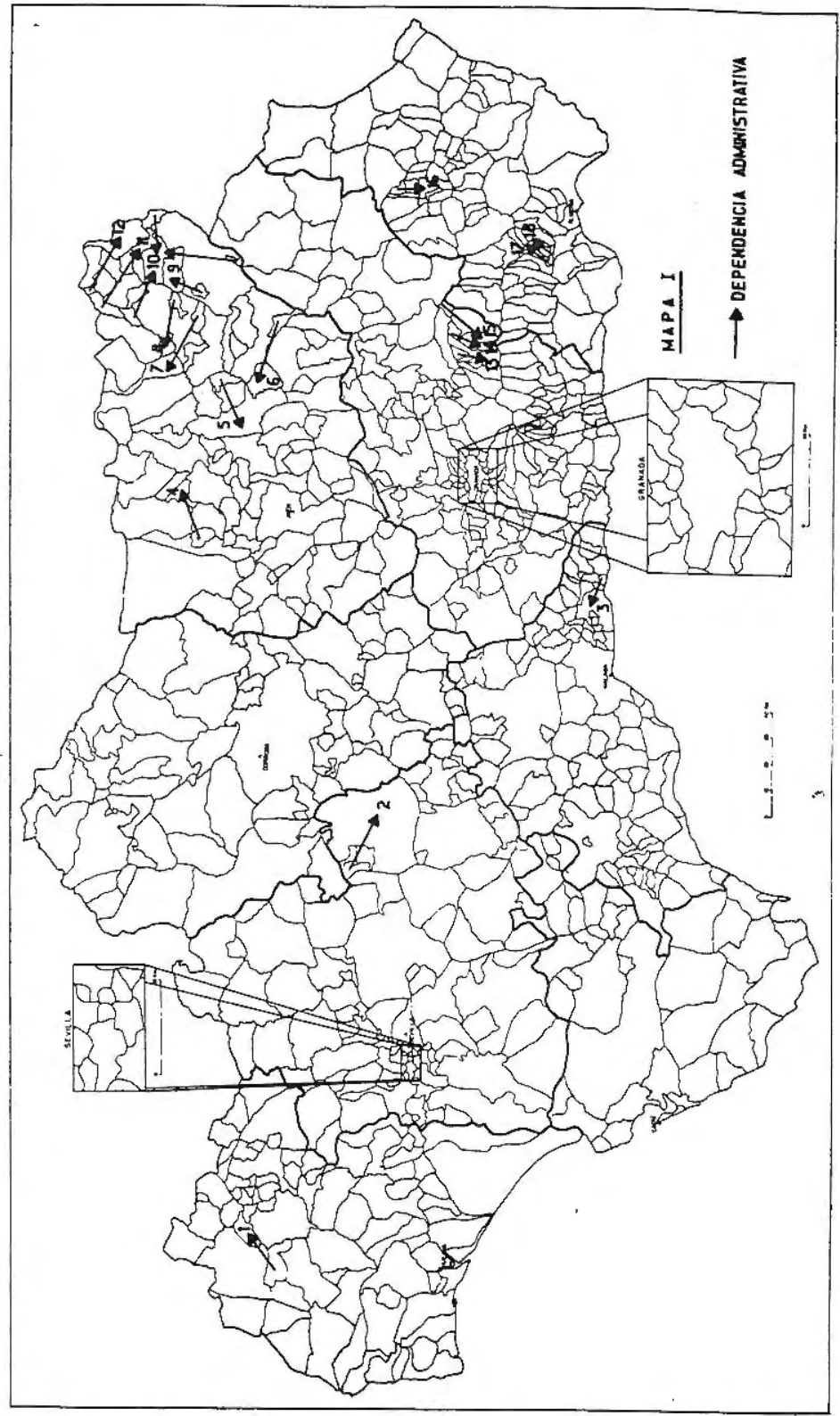

Fuente: Cano García (1990) y elaboración propia 
Los términos discontinuos, que hemos representado en el mapa I con indica ción del asentamiento capital, son relativamente frecuentes en Andalucía, sobr todo en zonas montañosas como el Prebético jiennense, donde se localiza 1 . mayoría de ellos. Es ésta una zona en la que tradicionalmente han fluctuado lo límites de Andalucía y que ha estado marcada por la presencia de señoríos dı órdenes militares, en concreto la de Santiago desde época de Sancho IV en e siglo XIII (CANO GARCIA, 1987), lo que ha favorecido, junto con un medic agreste, la fragmentación municipal. En general corresponden a dos unidade: territoriales diferenciadas, de extensión bien similar (caso de Cortegana en Huel va) o bien desequilibrada (cuyo ejemplo sería Ecija en Sevilla), aunque tambiér encontramos municipios divididos hasta en cuatro subunidades (Segura de la Sierra en Jaén).

Además debemos tener en cuenta que en esta cartografía sólo se han reflejadc los casos más evidentes, pues, con menor importancia, aparecen en un númerc más elevado de municipios, tal y como recoge el Mapa Topográfico de la Comunidad Autónoma de Andalucía 1:300.000 (JUNTA DE ANDALUCIA, 1984-b) La leyenda del mismo presenta este tipo de situaciones -en un total de 64 enclaves- para todas las provincias andaluzas a excepción de Cádiz, si bien muchas de ellas son meras jurisdicciones que ni siquiera tienen una toponimia específica. La relación de los 18 casos municipales que aquí hemos destacado se recoge en uno de los anexos finales.

De todos modos lo importante de este fenómeno son las consecuencias que tiene para la prestación de servicios públicos, que tienden a abandonarse en las zonas desenganchadas del lugar central, al que sin embargo se debe acudir para cualquier gestión administrativa. Cabe decir, no obstante, que la problemática no es alta dada la escasa población de las áreas desintegradas: unos 3.957 hab. de derecho en 1981 según el Inventario toponímico del Mapa Topográfico de Andalucía Escala l:300.000 (JUNTA DE ANDALUCIA, 1989-a), repartidos en 17 lugares de asentamiento, no siempre recogidos por el Nomenclator como entidades de población y por tanto de los que desconocemos su población exacta.

Mucho más complejo es el caso de los llamados núcleos secesionistas. Este fenómeno, aunque no es nuevo, ha tomado mayor virulencia en los últimos tiempos, en gran parte como reacción a la tendencia concentradora que se desarrolló con fuerza durante la dictadura (en la década de los setenta se redujo el número de municipios andaluces en 35).

En la actualidad el total de ayuntamientos en Andalucía asciende a 768, resultado de añadir, a los 761 que recogía el Censo de 1981 (I. N. E., 1984), 8 nuevos términos, y restar una agregación municipal (Beninar a Berja en Almería). De los 8 nuevos ayuntamientos, 6 han sido constituidos por Decreto del Consejo de Gobierno de nuestra Comunidad Autónoma (La Mojonera segregado 
de Félix en Almería; Cañada del Rosal de La Luisiana en Sevilla; Torremolinos de Málaga capital; y Benalup -la antigua Casas Viejas de la II. ${ }^{a}$ República- de Medina-Sidonia en Cádiz), mientras que 2 (El Ejido de Dalías en Almería y Cuevas del Campo de Zújar en Granada) aparecieron con anterioridad al traspaso de competencias. Por su parte el número de segregaciones que hasta el momento han sido denegadas por uno u otro motivo asciende a un total también de 8 .

Las causas de estos movimientos separatistas son varias, pero en general derivan de una compleja estructura de poblamiento que determina el olvido de los servicios públicos en los núcleos menores o simplemente alejados de la capital municipal. Ello ha llevado a muchas entidades a iniciar procesos de segregación para intentar solventar su particular problemática. La tipología de núcleos secesionistas (ver mapa II) sería, en nuestra opinión, la siguiente (VENTURA FERNANDEZ, 1988):

a) Antiguas agregaciones o fusiones de municipios que pretenden ahora deslindarse por parte del núcleo que se siente más desfavorecido. Son frecuentes en Granada (Yegen, Cónchar, Bellicena y Ambroz,...) y Jaén (Garcíez, Cárchel).

b) Núcleos litorales en expansión por su desarrollo turístico. Aparecen lógicamente en las provincias de Granada (Torrenueva), Málaga (Torremolinos, Torre del Mar, San Pedro de Alcántara) y Huelva (La Antilla, La Redondela).

c) Entidades con una dinámica económica distinta a la de su capital municipal, fruto normalmente de la colonización interior. Son, por lo general, pueblos con una fuerte actividad agraria (Villafranco del Guadalquivir) o minera (Tharsis).

d) Pedanías insertas en municipios muy extensos que sufren una situación de marginalidad. Las encontramos en términos como Antequera, Córdoba o Jerez, entre los que destaca el caso de hąa Barca de la Florida en este último municipio.

e) Centros de población surgidos al abrigo de vías de comunicación, bien sea líneas férreas (Bobadilla) o carreteras (El Cuervo).

Como se aprecia en el mapa la gran mayoría de los núcleos segregacionistas se sitúa sobre el oriente andaluz, ya que allí confluyen dos de las principales causas de estos movimientos independentistas: las agregaciones forzadas de décadas anteriores y la expansión de asentamientos turísticos litorales. Sin embargo ninguno de esto núcleos coincide con los enclaves discontinuos que veíamos en el mapa I. 


\section{MAPA II}

PRINCIPALES NUCLEOS SEGREGACIONISTAS DE ANDALUCIA

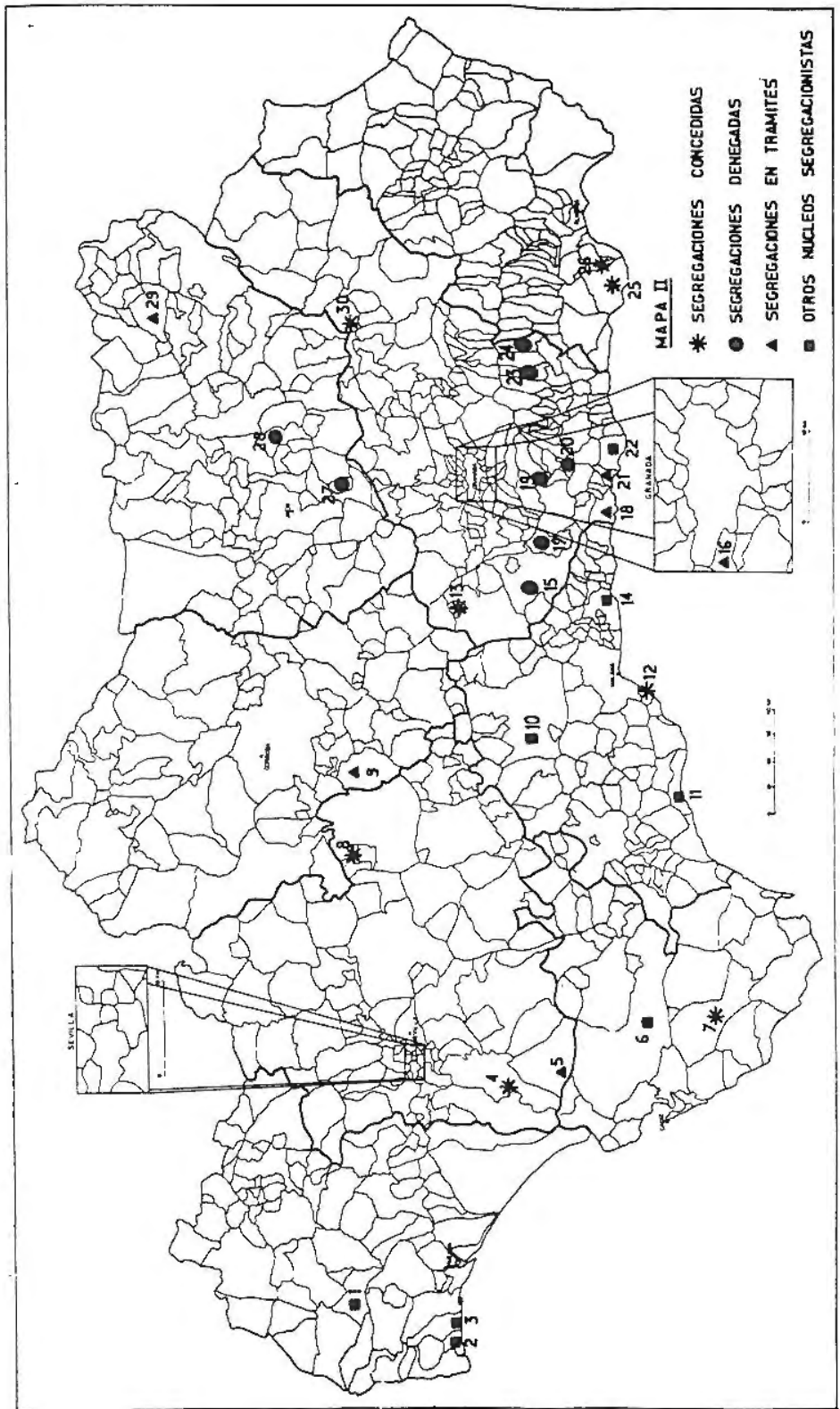

Fuente: D.G. de Administración Local y Justicia de la Junta de Andalucía y elaboración propia. 
En la actualidad, y dada la magnitud del fenómeno ( 6 expedientes en trámites para la segregación y más de 40 núcleos asociados en una Coordinadora de Pueblos por su Autonomía), la actitud de la Administración Autónoma es más restrictiva que en los últimos años, argumentando posibles pérdidas en la calidad de los servicios prestados a los ciudadanos por los nuevos ayuntamientos. Los tintes políticos del conflicto son también evidentes a la hora de conceder o no una segregación.

En cualquier caso estamos a la espera de una ya bastante demorada Ley de Demarcación Territorial que establezca criterios estables para todos estos procesos. Al parecer, para poder acceder a la independencia municipal será necesario un mínimo de 5.000 habitantes, $10 \mathrm{~km}$. de distancia a la entidad capital y evidente capacidad de autogestión económica. Según estos criterios, a los que se opone la Coordinadora de Pueblos por restrictivos y la Federación Andaluza de Municipios y Provincias por permisivos, sólo se aprobaría -como comprobamos en el cuadro adjunto- el actual expediente de segregación de El Cuervo (en Lebrija, Sevilla).

\section{CUADRO I}

ENTIDADES DE POBLACION QUE TRAMITAN EXPEDIENTE DE SEGREGACION EN LA CONSEJERIA DE GOBERNACION

\begin{tabular}{llcrr}
\hline Entidad & Municipio $^{1}$ & Provincia & Población & Distancia $^{2}$ \\
\hline Bellicena y Ambroz & Vegas del Genil & GR & 1.300 hab. & $1,5 \mathrm{~km}$. \\
Lobres & Salobreña & GR & 890 hab. & $3,7 \mathrm{~km}$. \\
La Herradura & Almuñécar & GR & 2.920 hab. & $9 \mathrm{~km}$. \\
El Cuervo & Lebrija & SE & 7.200 hab. & $10 \mathrm{~km}$. \\
Arroyo del Ojanco & Beas de Segura & $\mathrm{J}$ & 2.478 hab. & $14 \mathrm{~km}$. \\
La Guijarrosa & Santaella & CO & 504 hab. & $9 \mathrm{~km}$. \\
\hline
\end{tabular}

Fuente: Dirección General de Administración Local y Justicia de la Consejería de Gobernación de la Junta de Andalucía. 


\subsection{Agrupaciones municipales ${ }^{3}$}

Muy relacionado con estos aspectos jurídico-administrativos se encuentra el tema de las distintas posibilidades de asociación municipal que encontramos hoy por hoy en Andalucía. Estas agrupaciones intermunicipales se pretenden fomentar por parte de la Administración para la mejor organización de los servicios públicos sobre el territorio, dependiendo también su regulación final de la mencionada Ley de Demarcación Territorial de Andalucía. Además, una vez parece que definitivamente olvidado como tal el proyecto de comarcalización, correspondería a estas figuras cubrir el escalón territorial intermedio entre los municipios y las provincias; o incluso convertirse en un posible estadio de transición hacia un proceso comarcalizador a largo plazo, de modo que solventen momentáneamente las tensiones en la Ordenación del Territorio (MURO i BAS, 1989).

Los tipos de asociaciones de municipios son fundamentalmente tres: las mancomunidades, los consorcios y las áreas metropolitanas (NAVARRO y VENTURA, 1990). Las mancomunidades las podemos definir como organismos supramunicipales constituidos por distintos ayuntamientos voluntariamente asociados para prestarse servicios mutuamente y desarrollar obras de interés social común. Sobre el territorio andaluz aparecen en la actualidad 29 mancomunidades configuradas de manera efectiva, mientras 7 se encuentran en trámites de consolidación (JUNTA DE ANDALUCIA, 1989-b), especializándose cada una de ellas en la gestión de determinados servicios públicos. Cabe decir aquí que parece ésta una figura bastante interesante para la resolución de problemas que muchos ayuntamientos, por múltiples motivos (escasa extensión, despoblación y empobrecimiento o, por el contrario, ocupación intensiva), tienen dificultades para afrontar de manera autónoma.

Los consorcios son acuerdos entre entidades locales y organismos de la Administración Pública (universidades, ICONA, confederaciones hidrográficas,...) para fines de interés común; o incluso con entidades privadas sin ánimo de lucro que busquen objetivos sociales semejantes. En todo caso estos acuerdos están -para el caso andaluz- auspiciados siempre por las distintas diputaciones provinciales, que ejercen la tutela en la constitución y desarrollo de los mismos. Hasta el momento ha sido la Diputación Provincial de Jaén la más activa, ya que ha logrado organizar 15 consorcios sobre el total de 25 establecidos actualmente en Andalucía, implicando al 75\% de los municipios jiennenses en alguno de ellos.

Por último señalar que las áreas metropolitanas no se encuentran todavía

3. Se trata de realizar aquí una sucinta aproximación a un tema que debe enfocarse con mayor profundidad desde el punto de vista de la Geografía de la Administración. 
plenamente constituidas en ningún ámbito de nuestra Comunidad, aunque hay espacios que presentan características próximas a las que pueden determinar la aparición de esta figura (urbanización intensiva, especialización secundaria y terciaria, densidad de población elevada, asentamientos satélites). Nos estamos refiriendo a los casos del entomo de Sevilla capital, Hoya de Málaga, Vega de Granada, Bahía de Cádiz o Campo de Gibraltar, si bien es el primero de ellos (donde se concentra el $12 \%$ de la población andaluza) el que alcanza una gestación más avanzada (ALMOGUERA SALLENT, 1989), e incluso se ha delimitado territorialmente para la "Coordinación de las políticas urbanísticas municipales" (JUNTA DE ANDALUCIA, 1984-a). El respeto a los intereses de los pequeños ayuntamientos es quizás el principal problema con el que se enfrenta esta conflictiva figura de la administración territorial.

\section{LA SEGREGACION DE ISLA MAYOR-VILLAFRANCO DEL GUADALQUIVIR}

\subsection{Herencia histórica}

La Isla Mayor del Guadalquivir es una unidad fisiográfica enmarcada entre dos de los tres brazos en los que diverge nuestro río grande en su tramo final: el de la Torre al oeste y el cauce central, convertido en principal a raíz de las rectificaciones y obras de drenaje que sobre él se han efectuado en los dos últimos siglos. Administrativamente pertenecía en su totalidad al antiguo municipio de Puebla del Río - en la provincia de Sevilla-, asentándose su núcleo capital sobre la plataforma miocénica del Terciario y extendiéndose longitudinalmente hacia el sur hasta abarcar los terrenos marismeños de las "islas" del Guadalquivir (Mayor, Menor y Mínima) (CANO GARCIA).

Ha sido ésta una zona dedicada tradicionalmente a la explotación ganadera de caballos y toros de lidia, que sin embargo en las últimas décadas ha sufrido una intensa transformación agraria. Alteración de usos que hunde sus raíces en la mitad de la pasada centuria cuando estas tierras pasan a manos privadas de grandes hacendados, pero que toma carta de naturaleza a finales de la década de los veinte al ser adquiridas por capital internacional para su explotación agrícola. Así, la compañía de las lslas del Guadalquivir, llamada de los ingleses por la dirección de Mr. Fisher y la presencia mayoritaria de técnicos de esta nacionalidad aunque el capital esencial fuese suizo y francés, compró la Isla Mayor al marqués de Casa Riera y la Mínima (originada en 1888 a través de la ejecución de la corta de Los Jerónimos sobre los meandros del Mármol y la Ermita) al de 
Olasso, con la idea de convertirlas en un nuevo valle nilótico basado en el cultivo del algodón. Pero el fracaso de esta explotación debido a que las plantaciones apenas daban rendimiento salvo en las vetas o zonas más consolidadas de la marisma, así como el afán especulativo de sus impulsores, hizo pasar la propiedad de unas manos a otras. No obstante, con anterioridad a nuestra Guerra Civil, ya se habían hecho pruebas satisfactorias con arroz, más adaptable a la salinidad de la tierra (RODRIGUEZ CARDENAS, 1991).

Fue precisamente el período bélico el que impulsó este cultivo, ya que la tradicional zona arrocera española -la albufera valenciana- había permanecido bajo control del gobierno de la República, mientras que el Bajo Guadalquivir fue rápidamente ocupado por las llamadas tropas nacionales. Es en esas fechas cuando Rafael Beca Mateos (R. Beca y Cía. Industrias Agrícolas, S. L. ), con la aquiescencia de las nuevas autoridades militares, compra la Isla Mayor para revenderla en lotes a colonos que la cultivarían de arroz a partir de 1937 y que gracias a las facilidades de pago accederían rápidamente a la propiedad de la tierra. Este proceso se acrecentó en la posguerra con la llegada de valencianos -mejores conocedores del cultivo-, hasta alcanzarse en la actualidad el $40 \%$ de la producción estatal de arroz. Lógicamente la ocupación del espacio fue también progresiva, primero en las zonas más septentrionales, para ir poco a poco penetrando en la marisma (RODRIGUEZ CARDENAS, 1991).

La principal herencia en cuanto a asentamientos de esta colonización interior son los poblados de Alfonso XIII (llamado Villa Guadiamar durante la II. ${ }^{\text {a }}$ República), al norte, y El Puntal (conocido ahora como Villafranco del Guadalquivir), más al sur. Ambas entidades, conscientes de su hecho histórico, económico e incluso cultural diferenciado, solicitaron ya en 1953 su constitución como municipio independiente de Puebla del Río, obteniendo tres años más tarde, por Decreto de 8 de junio del Ministerio de Gobernación (publicado el 19 de junio de 1956), la categoría de Entidad Local Menor bajo el nombre de Villafranco, que englobaba los dos núcleos anteriores y tenía su capital en El Puntal. En esta estadio de cierta autonomía más formal que real ha permanecido Isla Mayor hasta tiempos recientes, en los que, dentro del nuevo marco democrático, han rebrotado los sentimientos secesionistas.

\subsection{Problemática actual y proceso segregacionista}

A nadie se le escapa que este resurgir segregacionista se fundamenta en el diferencial de desarrollo infraestructural y de equipamientos de la entidad local respecto al núcleo capital del ayuntamiento matriz, que no está en corresponden- 
cia con la dinamicidad económica y consiguiente aportación recaudatoria de la zona. En los últimos años observamos un nuevo impulso de la explotación arrocera en su variedad índica (subvencionada por la CEE ante la demanda del norte de Europa), que a los 4 años de su introducción alcanza producciones medias de $7.500 \mathrm{~kg}$./ha., lo que supone un total de casi 200 millones de kgs. anuales para el antiguo municipio, y una facturación (a 45 pts./kg.) de unos 9.000 millones de pesetas. El millar de agricultores que se dedica a estas labores se organiza en un $90 \%$ en comunidades de regantes y en un $60 \%$ en cooperativas para el tratamiento de la producción (4 principales y 2 secundarias), si bien el "giganto" de la zona es la empresa HERBA, S.A. que comercializa el $90 \%$ de la producción y controla un porcentaje semejante de las semillas. Además, en los últimos 15 años se ha desarrollado con fuerza la explotación del cangrejo rojo de río, con una producción de más de 3 millones de kgs. anuales, por lo que, a un precio que oscila en torno a las 250 pts. $/ \mathrm{kg}$., se alcanzan facturaciones que rondan los 1.000 millones de pesetas, a los que habría que añadir unos 100 más procedentes de la pesca de anguilas, angulas y camarón. El número de pescadores implicados llega a los dos centenares, más unos 300 empleos, abrumadoramente femeninos, dedicados al tratamiento de una producción destinada sobre todo al mercado centroeuropeo ${ }^{4}$.

En este ambiente se creó la Comisión Pro-Segregación en 1983, convertida en AEPIMG (Agrupación Electoral Prosegregación de Isla Mayor del Guadalquivir) en las dos últimas legislaturas locales, cuando ha conseguido imponer su candidato a Alcalde pedáneo y los 4 miembros de la Junta Vecinal, así como alcanzar una excelente representación en el ayuntamiento de Puebla del Río. No olvidemos que en el último Nomenclator, el de 1981, la población de las entidades de Alfonso XIll y Villafranco superaba los 5.300 habitantes de hecho (672 la primera y 4.648 la segunda), frente a los poco más de 8.000 de Puebla capital. En el Padrón de 1986 el antiguo municipio llegaba a los 15.200 hab., de los que más de 7.000 eran isleños.

Fue la idea de presentar una moción de censura en el ayuntamiento matriz que diera el gobierno municipal a los representantes de las pedanías, lo que aceleró el proceso de segregación, de modo que el Decreto fue aprobado el 10 de febrero de 1988 por el Consejo de Gobierno de la Junta de Andalucía -con plenas competencias en la materia-, apareciendo publicado dos días después en el B. O. J. A. Es entonces cuando se plantean los problemas territoriales que aquí más nos interesan, puesto que al nuevo municipio le corresponden casi 11.000

4. Datos obtenidos a través de entrevistas personales con responsables de Soc. Coop. And. Veta La Mora e Islasur. S. A. 
has. -las mismas que se le venían asignando tradicionalmente a la entidad local menor-, permaneciendo algo más de 48.000 en Puebla, si bien la Administración Autónoma introdujo una mínima alteración sobre la propuesta de la Diputación Provincial de Sevilla para permitir la inclusión del cementerio de Villafranco, que curiosamente había quedado fuera de su propio término.

Pero como es lógico no es sólo un problema de cantidad sino también de calidad de tierras. En este sentido Villafranco reclama la unidad física de su municipio en torno a Isla Mayor (incluyendo también Isla Mínima), situación que dejaría muy mermado al de Puebla y sobre todo muy empobrecido en cuanto a su capacidad recaudatoria, ya que perdería gran cantidad de propiedades con un tipo impositivo medio catastral elevado (de más de 18.000 pts. por ha.): las de arrozal. En el mapa III observamos como, con el actual Decreto, el nuevo municipio de Isla Mayor resultaría enclavado, embolsado prácticamente por el de Puebla, sin acceso directo al cauce principal del Guadalquivir, en cuyas proximidades se sitúan las bombas de riego tan necesarias para las parcelas de cultivo, y sin alcanzar los límites del Preparque Este de Doñana (localizado en el extremo sur del antiguo municipio en lo que se conoce como Veta La Palma, y declarado en la actualidad Parque Natural por la Junta de Andalucía), por lo que no podría pertenecer al Patronato del Parque Nacional, donde defender los intereses de arroceros y cangrejeros. Por su parte Puebla argumenta la defensa de su propia supervivencia económica para conservar parte de su patrimonio marismeño en Isla Mayor (el dogal que vemos en el mapa) y no sólo en la Menor.

En el cuadro siguiente comprobamos como el inicial Decreto de Segregación no es equitativo, sino que tanto en superficie como, algo menos, en riqueza imponible, está desequilibrado en favor del municipio de Puebla. Las hectáreas clave, las de arrozal, se reparten a un 36,29 y 63,71\% entre Isla Mayor y Puebla respectivamente, lo que supone una base imponible de casi el doble para este último municipio. Esta situación estaría aparentemente compensada por la mayor presencia en Puebla de tierras de pastizal e improductivas, hecho que no es tan lacerante si tenemos en cuenta que éstas se sitúan en el mencionado Preparque Este con las consecuencias administrativas que ello trae consigo. 


\section{MAPA III}

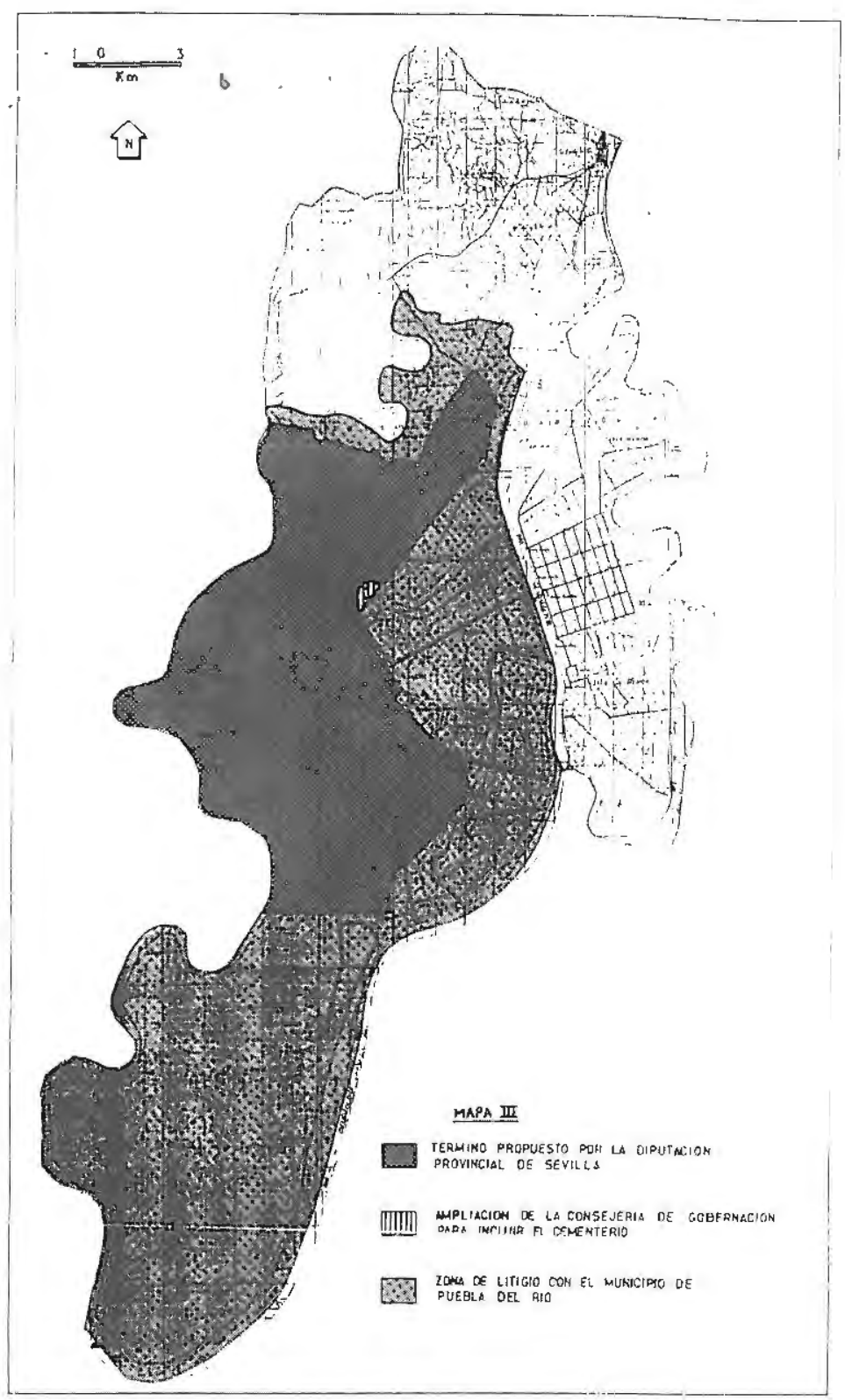

Fuente: Elaboración propia a partir de datos facilitados por la Junta de Vecinal de Isla Mayor del Guadalquivir. 


\section{CUADRO II \\ USOS AGRICOLAS COMPARADOS ENTRE LOS MUNICIPIOS DE ISLA MAYOR Y PUEBLA DEL RIO}

\begin{tabular}{|c|c|c|c|c|}
\hline \multirow[b]{2}{*}{ Cultivo } & \multicolumn{2}{|c|}{ Isla Mayor } & \multicolumn{2}{|c|}{ Puebla del Río } \\
\hline & Superficie & $\%$ & Superficie & $\%$ \\
\hline Arrozal & 9.342 & 36,29 & 16.399 & 63,71 \\
\hline Pastizal & 346 & 2,48 & 13.595 & 97,52 \\
\hline Labor Secano & 972 & 58,62 & 686 & 41,38 \\
\hline Labor Riego & - & 0,00 & 1.037 & 100,00 \\
\hline Eucaliptar & - & 0,00 & 728 & 100,00 \\
\hline Olivar & - & 0,00 & 281 & 100,00 \\
\hline Frutales, Agríos y Huer. & 一 & 0,00 & 122 & 100,00 \\
\hline Matorral & - & 0,00 & 49 & 100,00 \\
\hline Improductivo & 249 & 5,42 & 4.349 & 94,58 \\
\hline TOTAL HAS. & 10.909 & 22,65 & 37.246 & 77,35 \\
\hline RIQUEZA IMPONIB. & 177.701.128 Pts. & 34,66 & 3335.041.732 Pts. & 65,34 \\
\hline
\end{tabular}

Fuente: González. Gallego (1989).

Toda esta problemática llevó a la no aceptación del Decreto por parte de los interesados, y a la presentación de un recurso ante la Audienciáa Provincial de Sevilla, que anuló la segregación por defectos de forma al no cumplirse todos los trámites reglamentarios. Esto hizo a su vez que la Junta de Andalucía recurriera la sentencia ante el Tribunal Supremo, a lo que incluso se adhirieron los propios afectados como parte interesada. Nuestro Alto Tribunal tiene suspendido cautelarmente el Decreto, esperándose su fallo -del que se desconoce si entrará en cuestiones territoriales- para los próximos meses. Por todo ello el nuevo municipio ni siquiera se constituyó en circunscripción electoral independiente en los comicios locales de 1991. Como vemos, los problemas territoriales siguen estando presentes en los conflictos entre comunidades diferentes, aunque sea a escala local.

En suma, podemos concluir extrayendo algunas claves que serían extrapolables a un conjunto amplio de procesos segregacionistas, y que en nuestra opinión son éstas: 1) Aunque los condicionantes históricos o culturales pueden fomentar los movimientos secesionistas, son los diferenciales económicos y de desarrollo los elementos detonantes de los casos más activos; 2) No se trata de poseer un volumen más o menos cuantiosos de territorio, sino de controlar determinados 
espacios económicamente estratégicos; y 3) El papel de la Administración Pública no siempre es aséptico, sin que en ocasiones se trasluce la defensa de intereses políticos coincidentes.

\section{A MODO DE CONCLUSION}

Para finalizar diremos que hoy por hoy el estudio del poblamiento no puede enfocarse como la mera descripción de las formas de ocupación humana del territorio, sino que, considerando en todo caso su tendencia hacia Ia concentración, dispersión o diseminación, debe entenderse como una estructura de nodos jerarquizados y analizarse como un elemento básico para la organización del territorio a distintas escalas, tanto inframunicipal como comarcal. Así, el reconocimiento de las particularidades locales y la protección de las entidades menores (figura de la Administración Local poco explotada), constituyen aspectos esenciales para una correcta gestión pública. Por su parte el fomento de asociaciones intermunicipales en pie de igualdad entre sus distintos miembros, parece también imprescindible para la coordinación de servicios e infraestructuras de carácter común. 


\section{BIBLIOGRAFIA Y FUENTES DOCUMENTALES}

ALMOGUERA SALLENT, M. P. (1989): El área de Sevilla como sistema metropolitano. Sevilla, Instituto de Desarrollo Regional de la Universidad, 455 páginas.

CANO GARCIA, G. (1987): "Evolución de los límites de Andalucía y percepción del territorio". Geografia de Andalucia , tomo I (direc. y coord. G. Cano). Madrid, Ed. Tartessos, pgs, 49-121.

CANO GARCIA, G. (1990): "Divisiones territoriales y comarcalizaciones en Andalucía. Pasado y presente". Geografía de Andalucía, tomo VII (direc. y coord. G. Cano). Cádiz, Ed. Tartessos, pgs. 23-90.

CANO GARCIA, G. (en prensa): "Transformaciones agrarias y Ordenación del Territorio en Andalucía". Ponencia del curso Transformaciones agrarias en España en los últimos 40 años, organizado por la U. I. M. P. y celebrado en Alicante en mayo de 1991.

DECRETO de 8 de junio de 1956 por el que ese aprueba la constitución de una Entidad local menor, con Administración propia, en los poblados de Alfonso XIII y El Puntal, de la Isla Mayor del Guadalquivir en el municipio de Puebla del Río (Sevilla). Madrid, Boletín Oficial del Estado de 19 de junio de 1956, pg. 3946.

DECRETO 22/1988, de 10 de febrero, por el que se aprueba la segregación de la Entidad local menor de Villafranco del Guadalquivir, pertenenciente al municipio de La Puebla del Río, de la provincia de Sevilla, para constituirse en un nuevo e independiente municipio, con la denominación y capitalidad de Villafranco del Guadalquivir. Sevilla, Boletín Oficial de la Junta de Andalucía de 12 de febrero de 1988, pg. 483-484.

GONZALEZ GALLEGO, C. (1989): Estudio de la riqueza agricola de los términos municipales de Puebla del Río e Isla Mayor, en la provincia de Sevilla. Sevilla, Informe Técnico mecanografiado.

GONZALEZ JIMENEZ, M. (1980): En torno a los orígenes de Andalucia. Salamanca, Secretariado de Publicaciones de la Universidad de Sevilla, 164 páginas.

INSTITUTO NACIONAL DE ESTADISTICA (1984): Nomenclator de las ciudades, villas, lugares, aldeas y demás entidades de población. Censo de la Población de España de 1981. Madrid, cuadernos de las provincias andaluzas.

JORDA BORRELL, R. M. (1987) : "Población, economía y territorio en Andalucía". Geografía de Andalucía, tomo III (direc. y coord. G. Cano). Madrid, Ed. Tartessos, pgs. 137-206.

JUNTA DE ANDALUCIA (1983): Propuesta de Comarcalización. Documento para INformación Pública. Consejería de Política Tèrritorial y Energía, 199 páginas.

JUNTA DE ANDALUCIA (1984-a): Area metropolitana de Sevilla. Propuesta para la coordinación de las políticas urbanisticas municipales. Sevilla, Consejería de Política Territorial, 202 páginas.

JUNTA DE ANDAlUCIA (1984-b): Andalucía. Mapa Topográfico de la Comunidad Autónoma 1:300.000. Madrid, Consejería de Política Territorial, 2 hojas.

JUNTA DE ANDALUCIA (1986): Andalucía. Sistema de Ciludades. Sevilla, Consejería de Política Territorial, tomo I de 91 páginas.

JUNTA DE ANDALUCIA (1989-a): Imventario toponímico del Mapa Topográfico de Andalucia. Escala 1:300.000. Sevilla, Consejería de Obras Públicas y Transportes, 163 páginas.

JUNTA DE ANDALUCIA (1989-b): La experiencia de mancomunación de los servicios municipales en Andalucía (TEMCO consultores). Consejería de Obras Públicas y Transportes, estudio n.ํำ 386 - 2 volúmenes.

MARCHENA GOMEZ, M. (1984): La distribución de la poblacion en Andalucia (1960-1981). Sevilla, Diputación Provincial y Universidad, 187 páginas.

MARCHENA GOMEZ, M. (1987): "La densidad de población en Andalucía”. Geografía de Andalucía. tomo III (direc. y coord. G. Cano). Madrid, Ed. Tartessos, pgs. 123-135.

M. O. P. U. (1980): Divisiones territoriales en España, Madrid, C. E. O. T. M. A., 264 páginas.

MURO i BAS, X. (1989): "Mancomunidades y consorcios. Configuración legal actual y perspeetivas frente al minifundismo local". CEUMT, la revista municipal. Barcelona, Centro de estudios Urbanísticos Municipales y Territoriales, pgs. 28-34. 
NAVARRO LUNA, J. y VENTURA FERNANDEZ, J.(1990): "Areas según las asociaciones municipales", incluido en "Areas andaluzas homogéneas y heterogéneas". Geografía de Andalucía, tomo VIII (direc. y coord. G. Cano). Cádiz, Ed. Tartessos, pgs. 138-142.

OCAÑA OCAÑA, C. y GARCIA MANRIQUE, E. (1990): El Territorio Andaluz. Granada, Ed. Librería Agora, 239 páginas.

ORTEGA, Nicolás (1979): Política agraria y doninación del espacio. Madrid, Ed. Ayuso, 258 páginas.

RODRIGUEZ CARDENAS, M. (1991): La Isla Mayor del Guadalquivir a través de sus personajes.

Sevilla, C.P. Florentina Bon, 188 páginas

TYRAKOWSKI, Konrad (1988): "Principios del ordenamiento espacial al colonizar Sierra Morena entre 1767 y 1835. Un análisis geográfico". Las "Nuevas Poblaciones" de Carlos III en Sierra Morena y Andalucía (Avilés y Sena editores). Jaén, Servicio de Publicaciones de la Universidad de Córdoba y Seminario de Estudios Carolinenses, pgs. 75-90.

VENTURA FERNANDEZ, J. y AYALA JIMENEZ, J. (1987): "Concentración y dispersión. Características del poblamiento andaluz". Geografía de Andalucía, tomo III (direc. y coord. G. Cano). Madrid, Ed. Tartessos, pgs. 207-257.

VENTURA FERNANDEZ, J. (1988): "Problemas tertitoriales de los municipios andaluces". Revista de Estudios Andaluces, n. ${ }^{\circ}$ 10. Sevilla, Servicio de Publicaciones de la Universidad, pgs. 186-190.

\section{ANEXOS}

\section{Relación de principales municipios discontinuos de Andalucía}

\begin{tabular}{cll}
\hline N. en el mapa & Nombre del Municipio & Provincia \\
\hline 1 & Cortegana & Huelva \\
2 & Ecija & Sevilla \\
3 & Vélez-Málaga & Málaga \\
4 & Guarromán & Jaén \\
5 & Ubeda & Jaén \\
6 & Peal de Becerro & Jaén \\
7 & Castellar & Jaén \\
8 & Sorihuela del Guadalimar & Jaén \\
9 & Hornos & Jaén \\
10 & Segura de la Sierra & Jaén \\
11 & Orcera & Jaén \\
12 & Siles & Jaén \\
13 & Aldeire & Granada \\
14 & Ferreiras & Granada \\
15 & Dólar & Granada \\
16 & Purchena & Almería \\
17 & Bentarique & Almería \\
18 & Terque & Almería
\end{tabular}




\section{Relación de principales núcleos segregacionistas andaluces y situación del proceso.}

\begin{tabular}{|c|c|c|c|c|}
\hline N.. & Entidad & Municipio & Prov. & Situación \\
\hline 1 & Tharsis & Alosno & HUE & Inicial \\
\hline 2 & La Redondela & Isla Cristina & HUE & Inicial \\
\hline 3 & La Antilla & Lepe & HUE & Inicial \\
\hline 4 & Villafranco del G. & Puebla del Río & SEV & Concedida \\
\hline 5 & El Cuervo & Lebrija & SEV & En trámite \\
\hline 6 & La Barca de la Flo. & Jerez de la F. & CAD & Inicial \\
\hline 7 & Benalup & Medina-Sidonia & CAD & Concedida \\
\hline 8 & Cañada del Rosal & La Luisiana & SEV & Concedida \\
\hline 9 & La Guijarrosa & Santaella & COR & En trámite \\
\hline 10 & Bobadilla & Antequera & MAL & Inicial \\
\hline 11 & S. Pedro de Alcántara & Marbella & MAL & Inicial \\
\hline 12 & Torremolinos & Málaga & MAL & Concedida \\
\hline 13 & Zagra & Loja & GRA & Concedida \\
\hline 14 & Torre del Mar & Vélez-Málaga & MAL & Inicial \\
\hline 15 & Ventas de Zafarraya & Alhama de Granada & GRA & Denegada \\
\hline 16 & Bellicena y Ambroz & Vegas del Genil & GRA & En trámite \\
\hline 17 & Játar y Formes & Arenas del Rey & GRA & Denegada \\
\hline 18 & La Herradura & Almuñécar & GRA & En trámite \\
\hline 19 & Cónchar & Villamena & GRA & Denegada \\
\hline 20 & Izbor & El Pinar & GRA & Denegada \\
\hline 21 & Lobres & Salobreña & GRA & En trámite \\
\hline 22 & Torrenueva & Motril & GRA & Inicial \\
\hline 23 & Yegen & Alpujarra de la S. & GRA & Denegada \\
\hline 24 & Picena & Nevada & GRA & Denegada \\
\hline 25 & El Ejido & Dalías & ALM & Concedida \\
\hline 26 & La Mojonera & Félix & ALM & Concedida \\
\hline 27 & Cárchel & Carcheles & JAE & Denegada \\
\hline 28 & Garcíez & Bedmar y Garcíez & JAE & Denegada \\
\hline 29 & Arroyo del Ojanco & Beas de Segura & JAE & En trámite \\
\hline 30 & Cuevas del Campo & Zújar & GRA & Concedida \\
\hline
\end{tabular}

